\title{
Erratum to: Pre-alcoholic fermentation acidification of red grape must using Lactobacillus plantarum
}

\author{
Cristóbal A. Onetto • Edmundo Bordeu
}

Published online: 1 August 2017

(C) Springer International Publishing AG 2017

Erratum to: Antonie van Leeuwenhoek (2015)

108:1469-1475

DOI 10.1007/s10482-015-0602-4

In the original publication of the article, the word Lactobacillus plantarum in the article title appeared combined in the Springer website.

The correct title is given below,

Pre-alcoholic fermentation acidification of red grape must using Lactobacillus plantarum.

The online version of the original article can be found under doi:10.1007/s10482-015-0602-4.

C. A. Onetto - E. Bordeu

Departamento de Fruticultura y Enología, Pontificia Universidad Católica de Chile, Av. Vicuña Mackenna, 4560 Santiago, Chile

Present Address:

C. A. Onetto $(\square)$

School of Agriculture, Food and Wine, The University of

Adelaide, PMB 1, Glen Osmond, SA 5064, Australia

e-mail: cristobalonetto@gmail.com 